\title{
Letters
}

\section{A farewell to alms}

EDITOR-The recent UN prediction that its millennium development goals will be missed by a wide margin may stop the UN and its specialised agencies from adopting promethean goals they cannot hope to meet.

The G8 meeting is an opportunity to re-examine outmoded development principles. The Commission for Africa recommends a doubling of aid, reaching $\$ 75$ billion ( $£ 41$ billion; $€ 112$ billion) annually by 2015 and total debt forgiveness. ${ }^{2}$ Of the $\$ 75$ billion, $44 \%$ is directed towards health related millennium development goals.

However, the findings of the World Bank and the International Policy Institute show that traditional development aid does not work (box). ${ }^{3}{ }^{4}$ From 1990 to mid-2005 official development aid was more than $\$ 1$ trillion to developing countries. ${ }^{5}$ At least an equal amount has been contributed by foundations, religious organisations, corporations, and private donors. Oil exports from Africa now account for $11 \%$ of the world's supply while Africa's foreign direct investment has risen sharply to $10.1 \%$ of gross domestic product in 2004. Yet, the prime minister, Tony Blair, found that "African poverty and stagnation is the greatest tragedy of our time."'

The donor community does not lack money; its development concepts mean that increased aid will not eliminate global poverty but is more likely to increase it. ${ }^{4}$ The US African Growth and Opportunity Act reduced barriers to trade, increased exports, created jobs, and expanded opportunities for

\section{A tale of two studies}

\section{World Bank 1999}

Does not adequately assess borrowers' capacity to implement planned projects Does not assess the demand for health services adequately

Knows little about what it has "bought" with its investments

International Policy Institute $\mathbf{2 0 0 5}^{\mathbf{4}}$ Aid has generally failed to achieve its stated goals

Aid has undermined democracy and delayed policy reforms that would have benefited the poor

India and China have achieved rapid and sustained economic growth despite receiving trivial amounts of aid

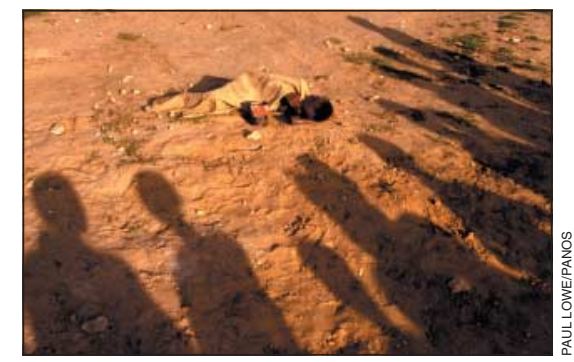

human resources. ${ }^{1}$ The resulting outflow of human resources from those countries with the highest disease burden is one example of how healthcare knowledge and capacity to apply that knowledge is being severely undermined. Another example is the agreement on trade related aspects of intellectual property rights (TRIPS), which effectively diminishes access to drug treatments by people who are least able to pay, but again, often in greatest need.

The debacle over the attempts of a consortium of 39 pharmaceutical companies to prevent South Africa from making generic drugs available to people with HIV/AIDS showed that moral outrage can be channelled productively. However, as long as outflows with high incentives and highly restricted inflows of health care and health knowledge continue, much more focus must be given to developing local solutions.

For example, in Malawi cadres of clinical officers and clinical assistants provide an important health force, and one that isn't offered the mobility conferred by an internationally recognised medical degree. In Ethiopia, local extension workers (who are not "health professionals") provide crucial front line health care. ${ }^{2}$ A study in Bangladesh found that again the use of local people-most of whom were not health professionals-dramatically increased children's survival. ${ }^{3}$ This achievement is beyond the ability of many other projects apparently "better resourced" with health professionals.

The gravity of globalisation, while pulling professional health workers further from those most in need of them, is also creating the necessary conditions for exploring new ways to deliver health care; ways that are possibly less expensive, more community focused, more empowering and, dare we suggest, possibly more effective.

Malcolm MacLachlan associate professor

Malcolm.maclachlan@tcd.ie

Eilish Mc Auliffe director

Centre for Global Health, Trinity College Dublin,

Dublin 2, Republic of Ireland

Competing interests: None declared.

1 Coombes R. Developed world is robbing African countrie of health staff. BMJ 2005;330:923. (23 April.)

\section{Developed world is robbing} Africa of health staff

New ways of delivering health care are needed in developing countries

EDITOR-Coombes says that the unwillingness of richer countries to train sufficient numbers of their own doctors and nurses is creating an international market in health
2 McAuliffe E, MacLachlan M. Turning the ebbing tide: knowledge flows and health in low-income countries Higher Educ Policy (in press).

3 Pyle DF, Hossain J. USAID-Municipality-Concern Worldwide Bangladesh child survival partnership program. Washington, DC: United States Agency for Internationa Development, 2004.

\section{There are no easy answers}

EDITOR-Many doctors from developing countries leave their homelands and prac- 
tices with the aim of acquiring knowledge and going back to practise in their countries-except for people fleeing from persecution.

While working in your own country you were used to fashioning a chest drain from a discarded drip set; you had to buy the catheter for that patient because otherwise he or she could not go to theatre; and you had to buy drugs on occasions when your salary hardly lasted a week.

Then, given the opportunity to either study or work in the West, you start to enjoy your work, although you work longer hours. You can get a chest $\mathrm{x}$ ray film within an hour, and you don't have to worry about your salary running out before the end of the month. You start to re-evaluate your life. You look at the priorities of the society you left behind-often it is not so poor that it cannot afford these things, but greed, corruption, and a total lack of political will has stopped any form of growth in health care. Even senior doctors are oblivious to what the world is about, and you despair.

African countries in particular need to start again. Africa has to be able to combine the 21st with the 19th century because that is how African development and its diseases are evolving. Western governments can help in technology transfer, not by building magnetic resonance scanners but by providing water for injections and life saving fluids and drugs and incorporating some form of maintenance system to the supply of modern technology to African countries.

Nuhu Usman specialist registrar acute medicine Birmingham Heartlands Hospital, Birmingham B9 5SS

kwajaffa@aol.com

Competing interests: None declared.

Coombes R. Developed world is robbing African countrie of health staff. $B M J$ 2005;330:923. (23 April.)

\section{Health of nations needs more than health} professionals

EDITOR-Socioeconomic imbalances have a habit of exacerbating themselves: we call them virtuous and vicious cycles. It is near impossible to change the one into the other.

The world is increasingly one integrated system, and costs and benefits are not directly linked. Those who benefit are not those who pay. Conscience may persuade some, some of the time, to pay for the value they receive. These discussions serve as part payment, a salve to conscience, but no pragmatist expects or believes that the brain drain will be reversed.

The convenient solution is to introduce friction to the free movement of health professionals: the health professionals pay; the benefiting countries say, "See, we have made it difficult for them"; and the losing countries are left with nothing.

The entire argument seems misplaced. Seen as a unit, the whole world suffers from a dearth of health professionals.

Poor countries-developing countriesneed more health, not more healthcare or more health professionals. Below a recog- nised threshold, health equates with income, both direct and indirect (the entire focus of public health initiatives: potable water, sewerage systems, electrification, telephones, roads, mass immunisation, etc.) and yet still the health of nations focuses on the movement of health professionals.

The health of a nation has little to do with the movement or the numbers or the training or the remuneration of health professionals: America and Cuba are proof of that.

I am in favour of dialogue, and I will award myself Brownie points for this piece; $I$ know that it will make no difference to the health of any nation, but I will feel better, and that will certainly be good for me.

Ebrahim Hassen locum specialist registrar, accident and emergency

North East Wales NHS Trust, Wrexham LL13 7TD doctor@drhassen.com

Competing interests: $\mathrm{EH}$ is a health professional.

1 Coombes R. Developed world is robbing African countrie of health staff. BMJ 2005;330:923. (23 April.)

\section{Damage $v$ ability to cope shapes need for disaster aid}

EDITOR-Redmond highlights important issues in assessing the needs of populations in humanitarian crises. ${ }^{1}$ The article puts into a refreshing and practical perspective the common misconceptions surrounding disasters, some of which have been noted by Noji. $^{2}$

Coordination and cooperation are the keys to maximising the international effort, and use of appropriate technology and due consideration to the dynamics of the local economy ensure sustainability. However, in discussing the prioritisation of needs in disasters, Redmond seems to have left out an often neglected but important needinformation. In such moments of great uncertainty, affected people need to be informed of current and emerging developments as well as how to personally care for their own health. This not only accords them a certain sense of personal responsibility for health, but also promotes trust for and cooperation with relief efforts.

The article also suggests that the threshold for "urgent action" is higher for children under 5 years ("emergency out of control") than for the general affected population ("serious condition"). If this is not an oversight it is worrying and worthy of further examination.

Finally, Redmond describes the impact of a disaster as the product of the number of people affected minus their ability and capacity to cope. Apart from being simplistic and mathematically flawed, this formula leaves one guessing how exactly to describe the number of people affected-is it mortality, displacements, vulnerability, or consequential morbidity?

The doubtful nature of the formula should, however, not distract from the fact that the need for international aid in disaster should be determined by weighing the extent of damage (however defined) against the local capacity to cope, a fact emphatically presented in this article.

Kelechi E Nnoaham public health specialist registrar North Oxfordshire Primary Care Trust Partnership Banbury Business Park, Adderbury, Oxfordshire

OX17 3NS

kelechi.nnoaham@noxon-pct.nhs.uk

Competing interests: None declared.

\section{Redmond AD. Needs assessment of humanitarian crises BMJ 2005;330:1320-2. (4 June.) \\ sequences of disasters. New} York: Oxford University Press, 1997.

\section{Aid after disasters}

\section{Economic considerations tend to take priority}

EDITOR-In their editorial van Ommeren et al show that reactions to natural disasters are delicate international matters. ${ }^{1} \quad$ Spiegel divided these disasters into natural disasters and complex emergencies. He cited political opinion or backlash as a predominant determining factor affecting response to these events. ${ }^{2}$ These responses, however, may instead be influenced more strongly by vested economic interest.

By Spiegel's definition, Iraq in 2003 should possibly have constituted a "complex emergency," as would Afghanistan. There would have been, by his definition, a reluctance to intervene in such crises. Complex emergencies may not be those that are merely politically risky; they may instead be economically risky.

Southeast Asia houses production lines that are immediately recognisable to the Western consumer, ${ }^{3}$ whereas sub-Saharan Africa does not boast these. When a tsunami hits Asia, it is a disaster because, aside from the profound human loss, it is an economic disaster too. Sudan's Darfur and the Democratic Republic of Congo, for example, offer little value to the middle European and American retailer. The extent of Western response to these is governed more by philanthropic emotion than by economics. The former is often shortlived, and initial projected pledges after a disaster fall by up to $60 \%$ when the funds are eventually paid. ${ }^{4}$

Spiegel's assertion that these areas are too remote for media access in this global arena of digital satellite imaging is surprising. If a disaster occurs in a region of any economic standing, then it is worthy of attention and assistance and so will receive both, but if it occurs in a region of lesser economic potential, then it seems to evolve into a complex emergency and response seems varied and inconsistent.

\section{Awori J Hayanga surgery resident}

Johns Hopkins Hospital, Baltimore, MD 21287,

USA

jhayang1@jhmi.edu

Competing interests: None declared.

1 Van Ommeren M, Saxena S, Saraceno B. Aid after disasters. BMJ 2005:1160-1 (21 May) 
2 Spiegel PB. Differences in world responses to natural disasters and complex emergencies. JAMA. 2005;293:1915-8

3 Sachs JD. The end of poverty. Economic possibilities for our time. New York: Penguin, 2005 .

4 Snow RW, Guerra CA, Noor AM, Myint HY, Hay SI. The Show RW, Guera CA, Noor AM, Myint HY, Hay SI. The

ciparum malaria Nature 2005:434:214-7.

\section{Evidence for psychosocial services needs strengthening}

EDITOR-The editorial by van Ommeren et al on aid after disasters is right on the mark. ${ }^{1}$ The psychosocial component in emergency relief action has increased recently. Donors clearly feel morally bound to provide funding for psychosocial relief, although many aid providers are not necessarily qualified for these services, in the process discrediting those who are.

From an epidemiological perspective, the evidence for these services needs strengthening. Moreover, the effectiveness of psychosocial interventions in postdisaster relief is unknown, raising questions on opportunity costs of this aid.

On a recent mission to Aceh after the tsunami, we analysed patients' records from a large Red Cross hospital between 11 and 31 January 2005 and interviewed several medical non-governmental organisations providing relief.

Out of 1174 consultations, 9.6\% (113 patients) had a psychiatric disease as the main diagnosis. Diagnoses ranged from anxiety, insomnia, and depression to psychosomatic disorders. No severe psychiatric illness was observed except for one patient with schizophrenia. Most patients were adults, and only eight ( $7 \%$ ) were aged 12 or younger. Better understanding of age related vulnerability would improve targeting psychosocial services.

We are convinced that psychological shock is an important and neglected issue after devastating events such as the tsunami. Losing family, home, and livelihood will traumatise a normal person in any culture, but time and natural resilience help most victims in their recovery. Nevertheless, some will require professional help, and severely ill patients from the period before the disaster will need continued care in the aftermath.

We were encouraged in Aceh by a few humanitarian agencies that were using pragmatic approaches to deal with victims of grief and hopelessness. They engaged victims in physical activities such as building their own homes and their lives. The victims themselves reported to us simply that they were able to sleep again after a day's work.

Debarati Guha-Sapir professor

Sapir@esp.ucl.ac.be

Wilbert van Panhuis research fellow

Centre for Research on Epidemiology of Disasters (CRED), Department of Public Health, Université catholique de Louvain, Brussels, Belgium

Joel Lagoutte medical director

ICRC Field Hospital, Banda Aceh, Aceh, Indonesia

Competing interests: None declared.

1 Van Ommeren M, Saxena S, Saraceno B. Aid after disasters. BMJ 2005:1160-1 (21 May).

\section{Coping with the aftermath of trauma}

NICE guidelines on post-traumatic stress disorder have fundamental flaw

EDITOR-Gersons and Olff discuss coping with the aftermath of trauma. ${ }^{1}$ The guidelines from the National Institute for Health and Clinical Excellence (NICE) that they mention conclude that early psychological intervention or debriefing does not prevent posttraumatic stress disorder, and might even be harmful. ${ }^{2} \mathrm{~A}$ significant reason for this is that a professional intervention can unwittingly embed a preoccupation with a traumatic event in the mind of the survivor (although intending the opposite) and thus impede forward momentum in getting back to normal.

Yet NICE is recommending trauma focused psychological therapy-which sits on the same conceptual territory as debriefing-as first line treatment for people identified as having post-traumatic stress disorder. I agree that formal cognitive behaviour approaches would be appropriate for a minority who develop, say, a handicapping phobic avoidance pattern after a traumatic event. But re-exposure to the details of the traumatic event, and the emotions evoked by it, is highly problematic as the standard therapeutic principle underpinning the whole specialism of traumatic stress and its body of practice.

I have seen numerous men after prolonged treatment at clinics for traumatic stress in London who have clearly been made worse. They have had repeated courses of therapy based on this re-exposure principle, with the result that a preoccupation with the past, a victim mindset, and erosion of a sense of personal agency and competence, have become highly salient as their sick role and sickness absence has extended, sometimes for years. This professionally directed attention to the past, and to "emotion," has become fundamentally antitherapeutic. The same thing has been noted on many US veterans of the Vietnam war with "chronic post-traumatic stress disorder."

What is needed is a pro-rehabilitation approach, tackling the future, aiming through graded normalisation to enable them to resumption of roles and activities that formerly had signified health and competence. $^{34}$ These NICE guidelines are storing up problems for the future.

Derek A Summerfield honorary senior lecturer Institute of Psychiatry, Maudsley Hospital, London SE5 8AP

derek.summerfield@slam.nhs.uk

Competing interests: None declared.

Gersons BPR, Olff M. Coping with the aftermath of trauma. BMJ 2005;330:1038-9. (7 May.)

2 National Institute for Health and Clinical Excellence. The management of post traumatic stress disorder in primary and management of post traumatic stress disor

3 Summerfield D. The invention of post-traumatic stress disorder and the social usefulness of a psychiatric category order and the social

Summerfield D. Cross-cultural perspectives on the Podicalisation or human suffering. In: Rosen G, ed Posttraumatic stress disorder. Issues and controversies. Chiches-

\section{Authors' reply}

EDITOR-Summerfield (and Hopkins et al, in their electronic response ${ }^{1}$ ) criticise the narrow, biomedical approach of the guidelines from the National Institute for Health and Clinical Excellence (NICE). Summerfield especially argues that the guideline is fundamentally flawed because the problems of a person, even many years after traumatic experiences, are framed within the diagnosis of post-traumatic stress disorder.

Psychological treatment for posttraumatic stress disorder does not pay attention to the whole life situation of such a person. Summerfield, on the basis of his clinical observations, recommends a rehabilitative approach for traumatised people. Hopkins et al, working with refugees, also say that this approach belittles people's suffering by construing it in purely psychopathological terms.

Both comments have a much wider importance: warning about not seeing a patient but only a "disease." But when regarding other diseases, such as diabetes, doctors are obliged to pay attention to the disease itself as well as the patient to improve his or her condition; for posttraumatic stress disorder the "denial" of the disorder is seen as morally necessary to "respect" the "survivor" of a trauma.

People working with refugees often regard diagnosing and even treating posttraumatic stress disorder as humiliating, as if such survivors are disabled from going on with their lives. People who survive the most terrible situations show strength and should be respected. But they also quite often develop the symptoms of post-traumatic stress disorder, which makes their adaptation to new circumstances difficult or even impossible. This dilemma is acknowledged in the NICE guideline in the small chapter on refugees. People who work with refugees and after war and terror should not forget the wholeness of a person and the complexities of day to day life but should also respect the need for psychological treatment to help the patient to adapt better to all the difficulties around.

Berthold P R Gersons professor of psychiatry b.p.gersons@amc.uva.nl

Miranda Olff associate professor of

psychotraumatology

Department of Psychiatry, Academic Medical

Center, University of Amsterdam, 1105 BC

Amsterdam, Netherlands

Competing interests: None declared.

1 Hopkins WB, Seltzer A, Avigaad J. NICE PTSD guidelines - not easily applicable to refugees. Electroni response to: Coping with the aftermath of trauma. bmj.com 2005. http://bmj.bmjjournals.com/cgi/eletters/ 330/7499/1038 (accessed 21 Jun 2005).

\section{bmj.com}

Letters appearing here are an edited selection of rapid responses originally posted on bmj.com

We ask for all letters to the editor to be submitted as rapid responses via bmj.com

For advice see: bmi.com/rapidresponses 